\title{
Incorporation of dopants in epitaxial SiC layers grown with fluorinated CVD chemistry
}

Pontus Stenberg, Erik J anzén and Henrik Pedersen

The self-archived version of this journal article is available at Linköping University Electronic Press:

http:/ / urn.kb.se/ resolve?urn=urn:nbn:se:liu:diva-138489

N.B.: When citing this work, cite the original publication.

Stenberg, P., J anzén, E., Pedersen, H., (2017), Incorporation of dopants in epitaxial SiC layers grown with fluorinated CVD chemistry, J ournal of Vacuum Science \&amp; Technology B, 35(3), .

https:// dx.doi.org/ 10.1116/ 1.4979279

Original publication available at:

https:/ / dx.doi.org/ 10.1116/1.4979279

Copyright: American Vacuum Society; 1999

http:// www.avs.org/ 


\section{Incorporation of dopants in epitaxial SiC layers grown with fluorinated CVD chemistry}

Running title: Dopants in SiC grwon with fluorinated CVD

Running Authors: Stenberg, Janzén and Pedersen

Pontus Stenberg, Erik Janzén and Henrik Pedersen

Department of Physics, Chemistry and Biology, Linköping University, SE-581 83 Linköping, SWEDEN

a) Electronic mail: henrik.pedersen@liu.se

Fluorinated chemistry in chemical vapor deposition (CVD) of silicon carbide (SiC) with $\mathrm{SiF}_{4}$ as $\mathrm{Si}$ precursor has been shown to fully eliminate formation of silicon clusters in the gas phase making $\mathrm{SiF}_{4}$ an interesting $\mathrm{Si}$ precursor. However, before a fluorinated CVD chemistry can be adopted, the effect of fluorine on the dopant incorporation must be understood since dopant incorporation is of paramount importance in semiconductor manufacturing. Here, we present dopant incorporation studies for n-type doping with $\mathrm{N}$ using $\mathrm{N}_{2}$ and p-type doping with $\mathrm{Al}$ using TMAl in fluorinated CVD of homoepitaxial $\mathrm{SiC}$. The precursors used were $\mathrm{SiF}_{4}$ as $\mathrm{Si}$ precursor and the source of $\mathrm{F}$ together with $\mathrm{CH}_{4}$ as $\mathrm{C}$ precursor. We find that it is possible to control the doping in $\mathrm{SiC}$ epitaxial layers when using a fluorinated CVD chemistry for both n- and p-type material using the $\mathrm{C} / \mathrm{Si}$ ratio as in standard SiC CVD. However, large area doping uniformity seems to be a challenge for a fluorinated CVD chemistry, most likely due to the very strong Si-F and Al-F bonds. 


\section{INTRODUCTION}

Silicon carbide ( $\mathrm{SiC}$ ) is a wide band-gap semiconductor with outstanding potential for high-temperature, high-power and high frequency applications. ${ }^{1,2}$ The hot wall, horizontal chemical vapor deposition (CVD) method is the most studied and best suited technique for growing the epitaxial layers which serve as the active region in all electronic SiC devices. ${ }^{3}$ The demands on the layers differ substantially between different applications, e.g. power devices require thick $(30-100 \mu \mathrm{m})$, low-doped $\left(10^{13}-10^{15} \mathrm{~cm}^{-3}\right)$ layers whereas high-frequency devices require thinner (in the $\mu \mathrm{m}$ range) layers with moderate doping $\left(10^{17} \mathrm{~cm}^{-3}\right)$. The standard approach to $\mathrm{SiC} \mathrm{CVD} \mathrm{is} \mathrm{to} \mathrm{use} \mathrm{silane,} \mathrm{SiH}_{4}$, and small hydrocarbons e.g. propane, $\mathrm{C}_{3} \mathrm{H}_{8}$, or ethylene, $\mathrm{C}_{2} \mathrm{H}_{4}$, as precursors diluted in a hydrogen carrier gas flow. The typical growth temperature is $1550-1650{ }^{\circ} \mathrm{C}$ rendering growth rates in the range $5-20 \mu \mathrm{m} / \mathrm{h}$ range. ${ }^{4}$ In order to increase the growth rate, mainly for production of high power devices, several routes to high growth rate SiC CVD has been explored. As SiC CVD is done in the mass transport controlled CVD regime, in order to increase the growth rate, the amount of $\mathrm{Si}$ and $\mathrm{C}$ growth species impinging the substrate surface must be increased. This is typically achieved by increasing the flow of the precursors into the CVD reactor. The main problem with a higher precursor flow is homogeneous gas phase nucleation, mainly formation of silicon droplets. This can be avoided by doing CVD at a lower total pressure which will in turn yield a lower partial pressure of Si, lowering the probability for Si droplet formation. ${ }^{5}$ Another route is to add a chemical species that outcompetes the formation of Si-Si bonds by forming bonds to $\mathrm{Si}$ stronger than the Si-Si bond. For this route, addition of chlorine has been studied in great detail, ${ }^{6}$ but it has also been shown that addition of bromine ${ }^{7}$ or fluorine ${ }^{8}$ have the same effect. 
Of paramount importance when depositing electronic device structures is the ability to control the amount of incorporated dopants in the material. Aluminum and nitrogen are the most common dopants in SiC for p-type respectively n-type doped layers. In SiC CVD these are typically introduced as trimethyl aluminum (TMAl) and dinitrogen $\left(\mathrm{N}_{2}\right)$. The substitutional incorporation of $\mathrm{Al}$ and $\mathrm{N}$ in the SiC lattice is controlled by the site-competition theory where $\mathrm{Al}$ is thought to replace $\mathrm{Si}$ and $\mathrm{N}$ is thought to replace $\mathrm{C}$ in the $\mathrm{SiC}$ lattice. ${ }^{9}$ This makes the $\mathrm{C} / \mathrm{Si}$ ratio in the CVD gas mixture the key parameter for controlling the amount of incorporated dopants. Doping incorporation in a chlorinated chemistry has been studied in detail and it was found that n-type doping by $\mathrm{N}_{2}$ and tertbutylphosphine (TBP: $\mathrm{C}_{4} \mathrm{H}_{9} \mathrm{PH}_{2}$ ) for doping with phosphorus was easily done and not affected by the presence of chlorine, ${ }^{10}$ while p-type doping by TMAl and triethylboron (TEB: $\left.\mathrm{B}\left(\mathrm{C}_{2} \mathrm{H}_{5}\right)_{3}\right)$ were both affected by the presence of chlorine which limited the maximum net carrier concentration to the low $10^{18} \mathrm{~cm}^{-3}$ range for $\mathrm{Al}$ doping and to the low $10^{19} \mathrm{~cm}^{-3}$ range for $\mathrm{B}$ doping. ${ }^{11}$ This was suggested to be due to formation of volatile monochlorides, $\mathrm{AlCl}$ and $\mathrm{BCl}$ at the $\mathrm{CVD}$ conditions, $1570{ }^{\circ} \mathrm{C}$ and 200 mbar. This is also supported by thermochemical modeling. ${ }^{12}$ This hypothesis is further supported by a p-type doping study in low temperature CVD of SiC with chlorinated chemistry at $1300{ }^{\circ} \mathrm{C}$, where the stability of $\mathrm{AlCl}$ is lower, ${ }^{12}$ where $\mathrm{Al}$ doping in the $10^{20} \mathrm{~cm}^{-3}$ range was measured by SIMS. ${ }^{13}$ Two overall conclusions from the doping studies with a chlorinated chemistry are that the C/Si ratio can still be used to control the doping and that chlorine seems to decrease the incorporation of p-type dopants. No detailed doping study has been done with a brominated chemistry, but it was reported that the net carrier concentration in the unintentionally doped layers were n-type, 
where the n-type conductivity stemmed from the background doping in the CVD reactor, decreased with a higher C/Si ratio in the CVD gas mixture into the reactor. ${ }^{7}$ This behavior is expected from the site competition theory. No doping studies have been reported for a fluorinated chemistry in SiC CVD. In this paper we present a study on how n-type doping by $\mathrm{N}_{2}$ and p-type doping by TMAl is affected by the presence of fluorine in the CVD process when using $\mathrm{SiF}_{4}$ as $\mathrm{Si}$ precursor for $\mathrm{SiC} \mathrm{CVD.}$

\section{EXPERIMENTAL}

For the growth of epitaxial SiC layers, a horizontal hot wall CVD reactor without rotation was used. The growth chamber was a $\mathrm{SiC}$ coated graphite susceptor with a gas cross section of $78 \mathrm{~mm} \times 24 \mathrm{~mm}$ in width and height, respectively, and a length of 190 $\mathrm{mm}$, which was preceded by a SiC coated widened graphite inlet after gas liner made of quartz. Substrates pieces of $4 \mathrm{H}-\mathrm{SiC}$ and a $4^{\circ}$ off-cut angle, $16 \mathrm{~mm} \times 16 \mathrm{~mm}$ in size, were placed at 3, 6 and $9 \mathrm{~cm}$ into the susceptor from the susceptor inlet. As precursors $\mathrm{SiF}_{4}$, $\mathrm{CH}_{4}$ and $\mathrm{N}_{2}$ or TMAl were used as $\mathrm{Si}, \mathrm{C}$ and $\mathrm{N}$ or $\mathrm{Al}$ precursors, respectively. $\mathrm{SiF}_{4}$ also acted as the source of $\mathrm{F}$. The precursors were diluted in Palladium membrane purified $\mathrm{H}_{2}$ acting as the carrier gas. For the experiments a carrier gas flow of 37.5 standard liters per minute (SLM) at a process pressure of 100 mbar was used. This gives a room temperature corresponding average gas speed velocity of $3.3 \mathrm{~m} / \mathrm{s}$ in the susceptor. The process temperature was $1600{ }^{\circ} \mathrm{C}$ and the $\mathrm{Si} / \mathrm{H}_{2}=0.125 \%$.

When investigating doping using $\mathrm{N}_{2}$, the $\mathrm{C} / \mathrm{Si}$ ratio was first fixed at 1.0 and the $\mathrm{N}_{2} / \mathrm{Si}$ ratio was varied from 0.1 to 10 , then the $\mathrm{N}_{2} / \mathrm{Si}$ was fixed at 1.0 and the $\mathrm{C} / \mathrm{Si}$ ratio was varied from 0.4 to 1.2 in steps of 0.2. Experiments where the $\mathrm{N}_{2} / \mathrm{Si}$ was reduced 
proportional to the $\mathrm{C} / \mathrm{Si}$ ratio to keep $\mathrm{N}_{2} / \mathrm{C}=1$ as the $\mathrm{C} / \mathrm{Si}$ was varied from 0.4 to 1.0 were also done. One additional experiment using $5 \mathrm{SLM}$ of $\mathrm{N}_{2}$ was made to supplement the series of increased $\mathrm{N}_{2}$ flow for a $\mathrm{N}_{2} / \mathrm{Si}$ ratio of 100 . To retain the average gas velocity and keeping the process pressure, the amount of carrier gas was reduced from 37.5 SLM to $32.5 \mathrm{SLM}$, otherwise keeping the flow rates of $\mathrm{SiF}_{4}$ and $\mathrm{CH}_{4}$, thereby resulting in a $\mathrm{Si} / \mathrm{H}_{2}$ ratio of $0.144 \%$ instead of $0.125 \%$. When investigating doping using TMAl the $\mathrm{C} / \mathrm{Si}$ ratio was kept at 1.0 while varying the $\mathrm{Al} / \mathrm{Si}$ ratio in the range from $10^{-5}$ to $10^{-2}$ and varying in the $\mathrm{C} / \mathrm{Si}$ ratio in the interval 0.4 to 1.2 in steps of 0.2 when $\mathrm{Al} / \mathrm{Si}=10^{-4}$.

For measurement of the net donor and acceptor concentration, capacitancevoltage measurements were used using a mercury probe station. The thickness of the grown epitaxial layers was approximated from the extension of triangular defects ${ }^{14}$ on the sample at least $2 \mathrm{~mm}$ away from the sample edge to avoid growth rate edge effects. The extension of the triangular defects was measured using optical microscope.

\section{RESULTS}

The samples were grown with a growth rate of 8.0-10.3 $\mu \mathrm{m} / \mathrm{h}$ (depending on the $\mathrm{C} / \mathrm{Si}$ ratio) measured on the sample positioned $3 \mathrm{~cm}$ from the inlet shown in Fig 1. On the average, the growth rate increased slowly as the C/Si ratio is increased. 


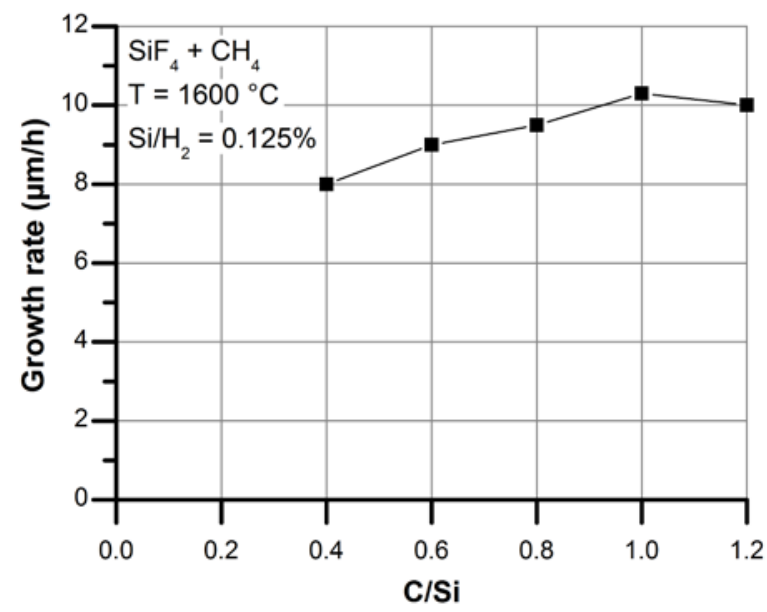

FIG. 1. Growth rate with varied C/Si ratio measured on the sample positioned $3 \mathrm{~cm}$ from the inlet.

\section{A. n-type doping using $\mathrm{N}_{2}$}

In the examined range of $\mathrm{N}_{2} / \mathrm{Si}$ ratio, the net donor concentration varies approximately linearly with the amount of dopant (Fig 2). By comparing the net donor concentration in the samples positioned at 3, 6 and $9 \mathrm{~cm}$ from the inlet, it is here also observed that the net donor concentration is higher further downstream in the susceptor. By lowering the $\mathrm{C} / \mathrm{Si}$ ratio from 1.2 down to 0.4 (Fig 3), the net carrier concentration increases approximately $3 / 4$ of a magnitude, i.e. almost 6 times higher incorporation, although the growth rate is reduced by $30 \%$. The incorporation is slightly enhanced even if the flow of $\mathrm{N}_{2}$ is reduced proportionally to the C/Si ratio (Fig 4). Even though the growth rate drops $30 \%$ the net donor concentration increases $30 \%$ - $50 \%$. 


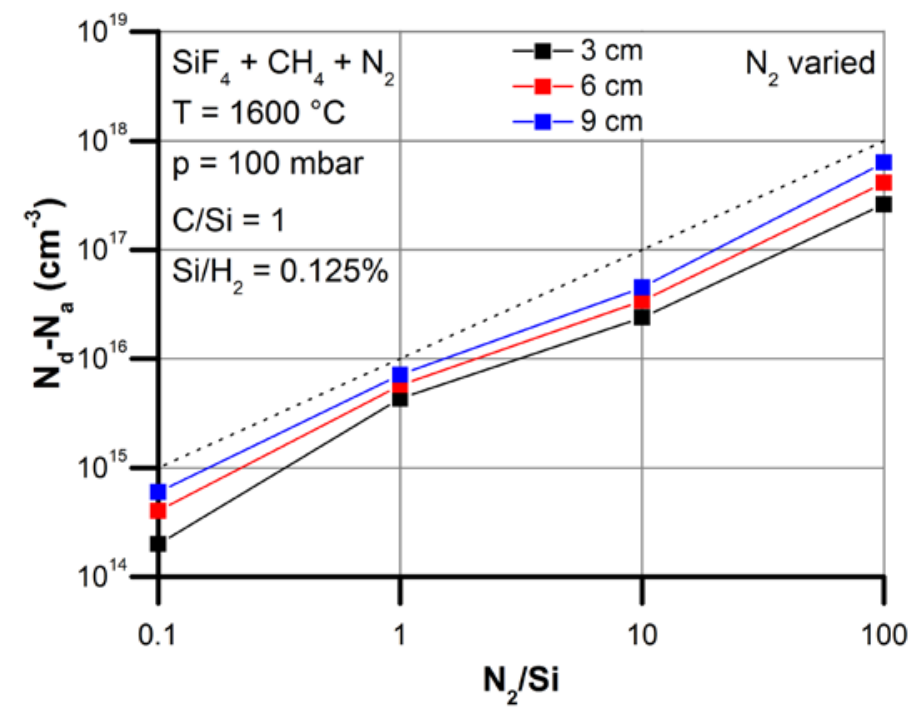

FIG. 2. Net donor concentrations when varying the $\mathrm{N}_{2} / \mathrm{Si}$ ratio. Since $\mathrm{C} / \mathrm{Si}=1$, this implies that $\mathrm{N}_{2} / \mathrm{Si}=\mathrm{N}_{2} / \mathrm{C}$. A trend of increasing net donor concentration can be seen as the $\mathrm{N}_{2} / \mathrm{Si}$ ratio is increased. Here, the result from the experiment using a reduced flow of $\mathrm{H}_{2}$ to compensate of the increased flow of $\mathrm{N}_{2}$ is plotted at $\mathrm{N}_{2} / \mathrm{Si}=100\left(\mathrm{Si} / \mathrm{H}_{2}=0.144 \%\right.$, 32.5 $\mathrm{SLM} \mathrm{H}_{2}$ instead of $\mathrm{Si} / \mathrm{H}_{2}=0.125 \%, 37.5 \mathrm{SLM} \mathrm{H}_{2}$ ).

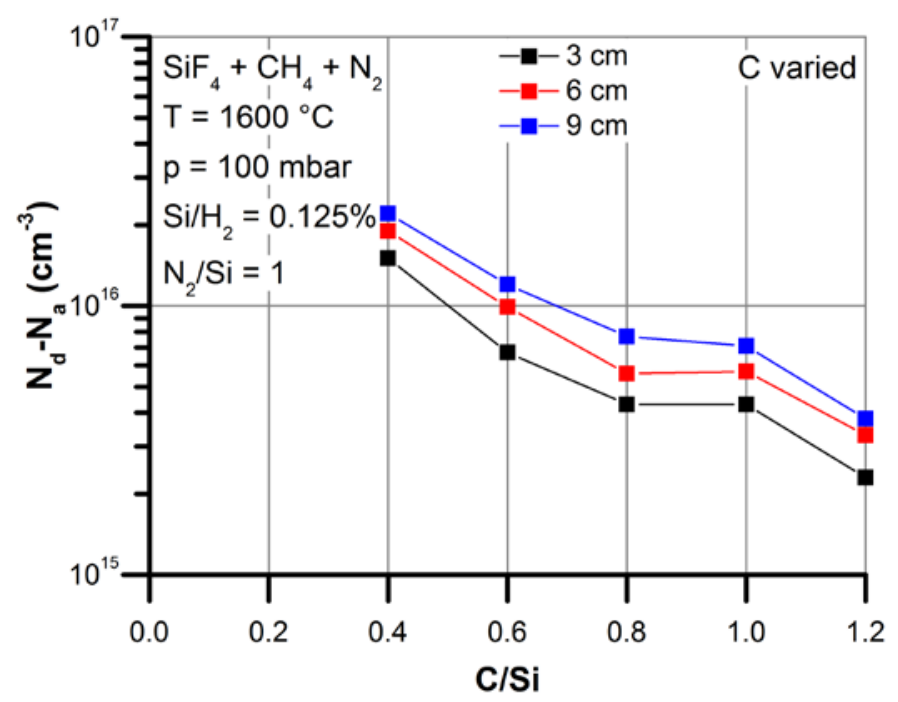

FIG. 3. Net donor concentrations when varying the C/Si ratio. On the average, the net donor concentration is observed to change oppositely to the C/Si ratio, i.e. a decreased net donor concentration can be observed for an increased C/Si ratio. 


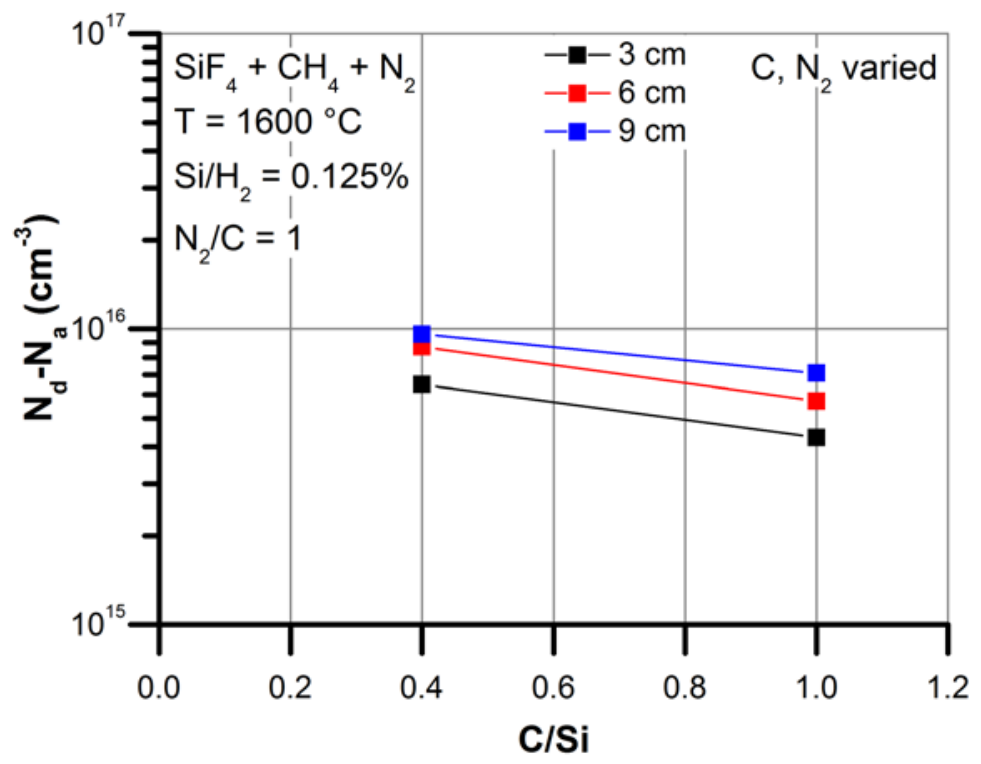

FIG. 4. Net donor concentrations when $\mathrm{N}_{2} / \mathrm{Si}$ and $\mathrm{C} / \mathrm{Si}$ reduced equally. A slightly oppositely change in net donor concentration to the $\mathrm{C} / \mathrm{Si}$ ratio, i.e. decreasing net donor concentration incorporation can be observed for an increased C/Si ratio.

\section{B. p-type doping using TMAI}

When TMAl is used for p-type doping the net acceptor concentration is approximately linear to the $\mathrm{Al} / \mathrm{Si}$ ratio in the interval of experiments (Fig 5). For the dependence on the $\mathrm{C} / \mathrm{Si}$ ratio, an increase of approximately $60 \%$ is observed as the $\mathrm{C} / \mathrm{Si}$ is increased from 0.4 to 1.2 (Fig 6). In this case, the net acceptor concentration should be put in the perspective of a $30 \%$ increased growth rate in the same interval, as was shown in Fig 1 . The net acceptor concentration for the $3 \mathrm{~cm}$ samples are significantly higher than the net acceptor concentrations for the 6 and $9 \mathrm{~cm}$ samples. For p-type doping using 
TMAl, the net acceptor concentration decreases along the susceptor, which is the opposite for the case for the incorporation of $\mathrm{N}$.

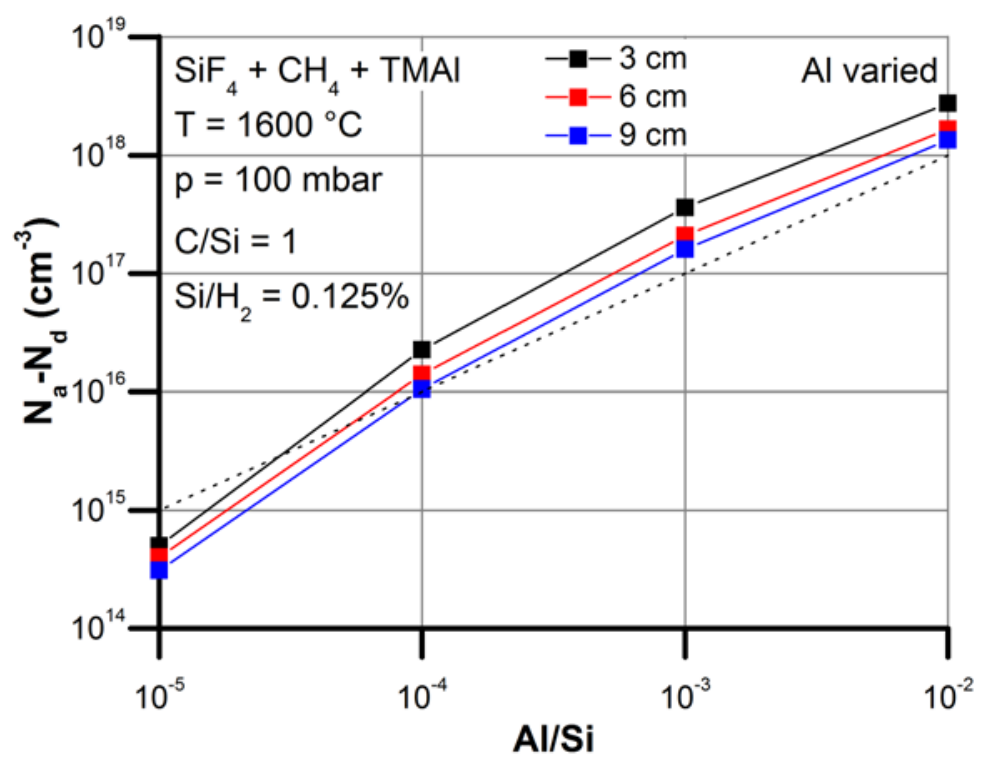

FIG. 5. Net acceptor concentrations when varying the Al/Si ratio. A trend of increased net donor concentrations can be observed for increased $\mathrm{Al} / \mathrm{Si}$ ratios.

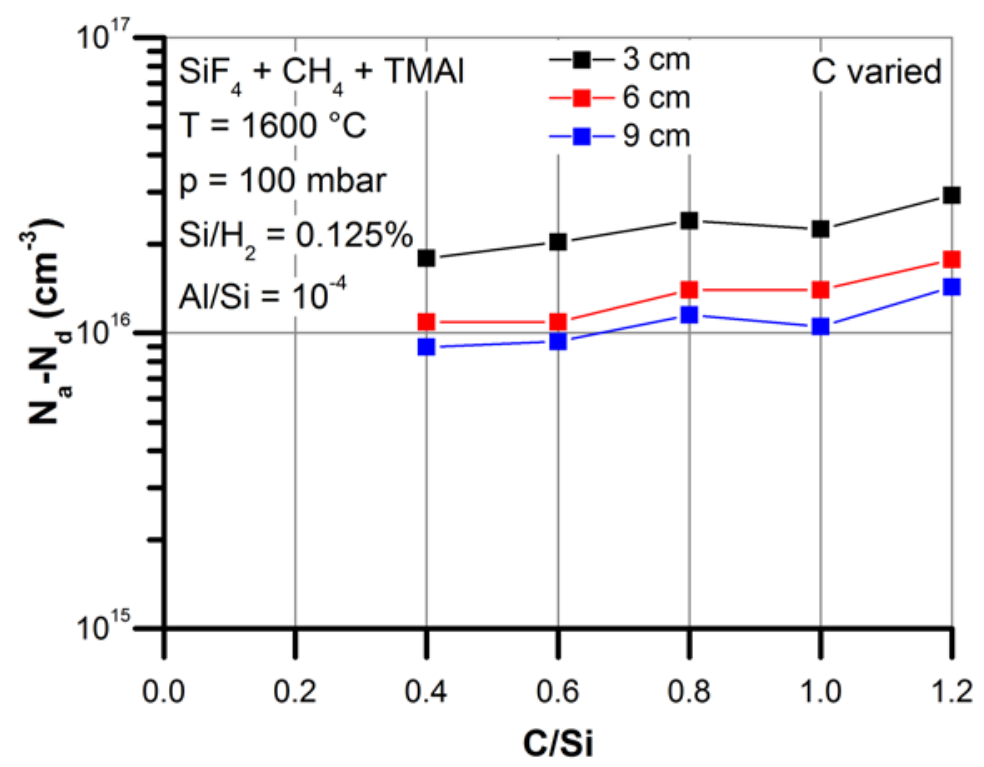

FIG. 6. Net acceptor concentrations when varying the $\mathrm{C} / \mathrm{Si}$ ratio. An increased net acceptor concentration can be observed for an increased C/Si ratio. Note the significantly higher net acceptor concentration at $3 \mathrm{~cm}$ from the inlet. 


\section{IV.DISCUSSION}

It is possible to see a slightly increasing growth rate as the $\mathrm{C} / \mathrm{Si}$ ratio is increased. The increase is though not proportional to the $\mathrm{C} / \mathrm{Si}$ ratio, indicating that the growth is in the Si limited regime. The slight increase of the growth rate is due to that the growth starts further downstream in the susceptor as the $\mathrm{C} / \mathrm{Si}$ ratio is increased. From the starting position of the growth, the growth rate decreases slowly along the susceptor, giving rise to a slightly higher growth rate at certain positions as the C/Si ratio is increased. ${ }^{15}$ It was ascribed to a changing effective $\mathrm{C} / \mathrm{Si}$ ratio that decreased along the susceptor, i.e. higher effective C/Si ratio upstream and lower effective C/Si downstream. The drop in growth

rate is most likely due to higher $\mathrm{F}$ content downstream, terminating the Si surface layer. ${ }^{16}$

As the net donor and acceptor concentrations followed the increment of $\mathrm{N}_{2}$ and TMAl, respectively, we assume that the net donor and acceptor concentration is from the incorporation of $\mathrm{N}$ and $\mathrm{Al}$, respectively, and thereby that the net donor and acceptor concentration is the $\mathrm{N}$ and $\mathrm{Al}$ concentration in the $\mathrm{SiC}$ lattice.

\section{A. n-type doping using $\mathrm{N}_{2}$}

Incorporation of $\mathrm{N}$ is controlled by the $\mathrm{C} / \mathrm{Si}$ ratio as seen for the $\mathrm{n}$-type doping using $\mathrm{N}_{2}$ when varying the $\mathrm{C} / \mathrm{Si}$ ratio (Fig. 3). Although the growth rate change of $30 \%$ in the $\mathrm{C} / \mathrm{Si}$ ratio range of 0.4 to 1.2 can affect the incorporation, the change of growth rate is fairly insignificant compared to the 6 times higher $\mathrm{N}$ incorporation in the same interval. It is also possible to observe an increase in the $\mathrm{N}$ incorporation further downstream along 
the susceptor. That goes well in hand with the suggestion that the effective C/Si ratio decreases along the susceptor. There can also be a chemical reason for this; that $\mathrm{N}$ containing dopant species are formed slowly. For the chlorinated chemistry is has been suggested by Cavallotti et al. that $\mathrm{SiN}$ is an important $\mathrm{N}$ dopant species. ${ }^{17}$ In the fluorinated chemistry the Si species is not formed in high concentrations. ${ }^{15}$ Together with the stable $\mathrm{N}_{2}$ molecule another reason for the increasing dopant incorporation along the gas flow can be that the kinetics of forming $\mathrm{N}$ dopant species is slow, thereby forming more such species downstream, creating a higher dopant concentration downstream. Albeit a low concentration of Si species and a high effective C/Si ratio, the dopant incorporation was still limited by the supply of $\mathrm{N}_{2}$, which could be seen by the linear relationship of dopant incorporation and the $\mathrm{N}_{2} / \mathrm{Si}$ ratio in Fig 2. Still in the $10^{17}$ range of $\mathrm{N}$ concentration, the inclusion of $\mathrm{N}$ is linear with the $\mathrm{N}_{2} / \mathrm{Si}$ concentration. The $\mathrm{C} / \mathrm{Si}$ ratio is therefore suggested to mainly be controlling the surface adsorption of the $\mathrm{N}$ dopant species, where a lower $\mathrm{C} / \mathrm{Si}$ ratio allows for a higher surface adsorption which is in line with the site competition theory ${ }^{9}$. The incorporation of $\mathrm{N}$ depending on the $\mathrm{C} / \mathrm{Si}$ seen in Fig 3 is approximately exponentially decaying (linear on the logarithmic scale used in the graph) in the studied $\mathrm{C} / \mathrm{Si}$ ratio interval while the $\mathrm{N}$ incorporation is approximately linear versus the $\mathrm{N}_{2} / \mathrm{Si}$ ratio seen in Fig 2 . In Fig 4 , where the $\mathrm{N}_{2} / \mathrm{C}$ ratio is kept constant and the $\mathrm{C} / \mathrm{Si}$ ratio is varied we see an increment in the incorporation, which we attribute to that the exponential behavior is dominant over the linear $\mathrm{N}_{2} / \mathrm{Si}$ behavior.

We have when using $\mathrm{N}_{2}$ for n-type doping in the fluoride chemistry identified two ways of controlling the dopant incorporation - changing the $\mathrm{C} / \mathrm{Si}$ ratio or changing the $\mathrm{N}_{2} / \mathrm{Si}$ ratio. If the process requires a special C/Si, there is a possibility to alter the $\mathrm{N}_{2} / \mathrm{Si}$ 
ratio to reach the targeted dopant concentration. The doping homogeneity over large areas is though poor, most likely due to varying effective C/Si ratio in the gas phase, affecting the surface.

\section{B. p-type doping using TMAI}

For the p-type doping with Al using TMAl, probably the most prominent difference compared to the n-type doping using $\mathrm{N}_{2}$ is that the $\mathrm{Al}$ incorporation is not as strongly dependent on the $\mathrm{C} / \mathrm{Si}$ ratio and that the doping concentration was showed to increase with the $\mathrm{C} / \mathrm{Si}$ ratio. Even taking into account that the growth rate could influence the incorporation, the result is in line with the site competition theory ${ }^{9}$. For the incorporation of $\mathrm{Al}$, higher doping levels are observed upstream where the effective $\mathrm{C} / \mathrm{Si}$ ratio is expected to be higher than downstream where the opposite conditions prevail. This could also be said to be in line with the site competition theory if the amount of $\mathrm{Al}$ dopant species are mainly the same along the susceptor. The Al dopant species was suggested by Cavallotti et al. to be the $\mathrm{Al}$ atom. ${ }^{17}$ As $\mathrm{HF}$ is present in the fluorinated chemistry, and the Al-F bond is stronger than the H-F bond with bond dissociation energies $675 \mathrm{~kJ} / \mathrm{mol}$ and $570 \mathrm{~kJ} / \mathrm{mol}^{18}$, respectively, it is possible that $\mathrm{F}$ forms a bond with $\mathrm{Al}$ in a similar manner as in the chlorinated chemistry where $\mathrm{AlCl}$ is expected to form, ${ }^{12}$ thereby reducing the amount of $\mathrm{Al}$ dopant species further downstream in the susceptor. If it would only have been the change in effective C/Si ratio (i.e. surface reactions) that influenced the $\mathrm{Al}$ incorporation there would not have been a significant higher dopant incorporation upstream (Fig 6) for the full range of C/Si ratios as the

effective C/Si changes along the susceptor. This indicate that another mechanism prevail 
as well, which we suggest is the reduced amount of atomic $\mathrm{Al}$ in the gas phase due to the formation of AlF species.

The drop in net acceptor concentration for lower concentrations of TMAl is most likely due to the n-type background in the reactor, but could also arise from reduced amount of atomic $\mathrm{Al}$ species at low $\mathrm{Al} / \mathrm{Si}$ ratios due to higher fraction of AlF species at low Al concentrations.

\section{SUMMARY AND CONCLUSIONS}

It is possible to control the doping in SiC epitaxial layers when using a fluorinated CVD chemistry for $n$ - and p-type material using the dopants $\mathrm{N}_{2}$ and TMAl, respectively. The dopant incorporation can be controlled by the amount of supplied dopants and by the $\mathrm{C} / \mathrm{Si}$ ratio, according to the site competition theory. The large area doping uniformity seems to be a challenge for a fluorinated CVD chemistry, likely due to the expected slow kinetics of the $\mathrm{SiF}_{4}$ precursor caused by the very strong Si-F bonds. We further believe that the gas phase chemistry plays an important role for the amount of created dopant species to be incorporated into the $\mathrm{SiC}$ lattice by reducing the amount of available $\mathrm{Al}$ through AlF formation.

\section{ACKNOWLEDGMENTS}

This work was supported by the Knut \& Alice Wallenberg Foundation (KAW) project "Isotopic Control for Ultimate Material Properties" and the Swedish Foundation for Strategic Research project "SiC - the Material for Energy-Saving Power Electronics" (EM11-0034). 
${ }^{1}$ J. A. Cooper and A. Agarwal, Proc. IEEE 90, 956 (2002).

${ }^{2}$ C. E. Weitzel, J. W. Palmour, C. H. Carter, K. Moore, K. J. Nordquist, S. Alien, C.

Thero and M. Bhatnagar, IEEE Trans. Electron Devices 43, 1732 (1996).

${ }^{3}$ A. Henry, J. Hassan, J. P. Bergman, C. Hallin and E. Janzén, Chem. Vapor Deposition 12, 475 (2006).

${ }^{4}$ O. Kordina, C. Hallin, A. Henry, J. P. Bergman, I. Ivanov, A. Ellison, N. T. Son and E.Janzén, Phys. Status Solidi B 202, 321 (1997).

${ }^{5}$ M. Ito, L. Storasta and H. Tsuchida, Appl. Phys. Expr. 1, 015001 (2008).

${ }^{6}$ H. Pedersen, S. Leone, A. Henry, O. Kordina, S. I. Nishizawa, Y. Koshka and E. Janzén, Chem. Rev. 112, 2434 (2012).

${ }^{7}$ M. Yazdanfar, Ö. Danielsson, E. Kalered, P. Sukkaew, O. Kordina, D. Nilsson, I. G. Ivanov, L. Ojamäe, E. Janzén and H. Pedersen, Chem. Mater. 27, 793 (2015).

${ }^{8}$ T. Rana, M. V. S. Chandrashekhar and T. S. Sudarshan, Phys. Status Solidi A 209, 2455 (2012).

${ }^{9}$ D.J. Larkin, P.G. Neudeck, J. A. Powell, and L.G. Matus, Appl. Phys. Lett. 65, 1659 (1994).

${ }^{10}$ H. Pedersen, F. C. Beyer, J. Hassan, A. Henry and E. Janzén, J. Crystal Growth 311, 1321 (2009).

${ }^{11}$ H. Pedersen, F. C. Beyer, A. Henry and E. Janzén, J. Crystal Growth 311, 3364 (2009).

${ }^{12}$ M.A. Fanton, B.E. Weiland and J.M. Redwing, J. Crystal Growth 310, 4088 (2008).

${ }^{13}$ B. Krishnan, S. P. Kotamraju, G. Melnychuk, H. Das, J. N. Merrett and Y. Koshka, J. Electron. Mater. 39, 34 (2010). 
${ }^{14}$ M. Yazdanfar, I. G. Ivanov, H. Pedersen, O. Kordina and E. Janzén, J. Appl. Phys. 113, 223502 (2013).

${ }^{15}$ P. Stenberg, P. Sukkaew, I. Farkas, O. Kordina, E. Janzén, L. Ojamäe, Ö. Danielsson and H. Pedersen, J. Phys. Chem. C 121, 2711 (2017).

${ }^{16}$ P. Stenberg, Ö. Danielsson, E. Erdtman, P. Sukkaew, L. Ojamäe. E. Janzén and H. Pedersen, submitted

${ }^{17}$ C. Cavallotti, F. Rossi, S. Ravasio and M. Masi , Ind. Eng. Chem. Res., 53, 9076 (2014).

${ }^{18}$ W. M. Haynes, CRC Handbook of Chemistry and Physics, 95th ed.; (CRC Press: Boca Raton, 2014). 